\title{
Relato de experiência do Pibid Interdisciplinar História, Geografia e Letras: olhares em convergência, vivências e aprendizados na educação básica
}

\author{
Experience report of the Interdisciplinary \\ Pibid History, Geography and Literature: views on \\ convergence, experiences and learning in basic education
}

Carlos Augusto Lima Ferreira* Leonardo Silva Santa Rosa Macêdo**

Lusanira Nogueira Aragão ${ }^{* * *}$

Sandra Cristina Queiroz Pinheiro ${ }^{* * * *}$

Resumo

O artigo apresenta um relato da experiência interdisciplinar vivenciada em duas escolas públicas do município de Feira de Santana, Bahia, desenvolvido pela Universidade Estadual de Feira de Santana (UEFS). Essas escolas são o lócus de atuação dos professores supervisores, espaço em que os bolsistas licenciandos tiveram o contato com a realidade escolar. O papel do supervisor do Pibid Interdisciplinar da UEFS é mediar o trabalho dos bolsistas de Iniciação a Docência, profes-

\section{Abstract}

The article presents a report of interdisciplinary experience lived in two public schools in the city of Feira de Santana, Bahia, developed by the State University of Feira de Santana (UEFS). These schools are the locus of action of the supervising teachers, space in which the scholarship students of UEFS had contact with the school reality. The role of the supervisor of the Interdisciplinary UEFS Pibid is to mediate the work of scholarship students, teachers and stu-

\footnotetext{
* Departamento de Educação e Mestrado e Graduação em História, Universidade Estadual de Feira de Santana (UEFS). Doutor em Educação, Universidade Autônoma de Barcelona (UAB). Coordenador do Pibid Interdisciplinar História, Geografia e Letras/ UEFS. caugusto@uefs.br ** Professor Supervisor, Colégio Estadual Maria José de Lima Silveira, Mestre em Zoologia, UEFS. leo.smacedo@gmail.com

*** Professora Supervisora, Escola Municipal José Tavares. Mestre em Ciências Ambientais, Programa de Pós-Graduação em Modelagem em Ciências da Terra e do Ambiente (PPGM)/ UEFS. lusaniranogueiraaragao@yahoo.com.br

**** Professora Supervisora, Escola Municipal José Tavares. Especialista em Metodologia do Ensino, Pesquisa e Extensão em Educação, Universidade do Estado da Bahia (Uneb). scqpinheiro2008@hotmail.com
} 
sores e alunos das escolas básicas, favorecendo o permanente diálogo e a troca de conhecimentos que contribuirão para um processo de ensino e aprendizagem significativo e contextualizado. As atividades desenvolvidas no Pibid Interdisciplinar permitiram que professores e alunos aperfeiçoassem, construíssem e reconstruíssem a leitura e reflexão dos diversos gêneros textuais promovendo neles a capacidade de argumentar, de posicionar-se criticamente sobre o que acontece no seu entorno e ao redor do mundo, contribuindo para a renovação do processo de ensino-aprendizagem. Palavras-chave: supervisores; interdisciplinaridade; experiências; formação. dents of primary schools, promoting permanent dialogue and the exchange of knowledge that will contribute to a process of teaching and meaningful learning and contextualized. The activities developed in Pibid Interdisciplinary allowed teachers and students to improve, construction and reconstruction the reading and reflection of various genres promoting in themselves the ability to argue, to position themselves critically about what happens in their surroundings and around the world, contributing to renewal of the teaching and learning process.

Keywords: supervisors; interdisciplinarity; experiences; training.

O Programa Institucional de Bolsas de Iniciação à Docência (Pibid), de acordo com a Capes (2013), é uma iniciativa para o aperfeiçoamento e a valorização da formação de professores para a educação básica. O programa concede bolsas a alunos das licenciaturas envolvidas nos projetos de Iniciação à Docência (ID) em parceria com escolas de educação básica da rede pública de ensino.

O programa visa promover a inserção dos licenciandos no contexto das escolas públicas na perspectiva de que desenvolvam atividades didático-pedagógicas sob orientação do professor da escola parceira, o/a professor(a) supervisor(a).

O projeto Pibid Interdisciplinar (História, Geografia e Letras) da Universidade Estadual de Feira de Santana (UEFS) tem como objetivo o desenvolvimento de projetos de ensino/extensão/pesquisa que dinamizem e atualizem a área pedagógica das graduações em História, Geografia e Letras, integrando interdisciplinarmente os professores coordenadores, supervisores e bolsistas ID comprometidos com o aperfeiçoamento da formação inicial e continuada. 
Deste modo, o Pibid Interdisciplinar da UEFS tem buscado viabilizar a realização de trabalhos voltados à valorização do local e à afirmação da identidade dos sujeitos. Assim, tem como perspectiva que os professores supervisores e os bolsistas ID percebam-se como professores-pesquisadores de sua própria atividade no ambiente escolar, inserindo-se de modo colaborativo na lida dos mais importantes desafios postos pela escola. Importante frisar que o papel do supervisor do Pibid Interdisciplinar da UEFS é mediar o trabalho dos bolsistas ID, professores e alunos das escolas básicas.

Este artigo apresenta um relato da experiência interdisciplinar vivenciado durante o ano de 2014 em duas escolas públicas situadas em zonas rurais do distrito de Maria Quitéria, município de Feira de Santana, Bahia: Escola Municipal José Tavares e Colégio Estadual Maria José de Lima Silveira.

O Pibid interdisciplinar pode representar um papel crucial no que tange ao processo de "fazer a Universidade", na medida em que possibilita a instituição de um espaço para discussões acerca das práticas da História, da Geografia e de Letras. Essas discussões inscrevem-se no âmbito das mudanças ocorridas nos campos das teorias específicas de cada licenciatura e no contexto educacional. A formação de parcerias e de intercâmbio de experiências, seja com outras instituições ou, principalmente, com os profissionais da educação básica, e a abertura de um campo de investigação/sistematização acerca dos sujeitos, saberes e práticas que configuram o fazer/aprender História, Geografia e Letras na microrregião onde se insere a UEFS, é essencial para um programa de iniciação à docência.

Nesse sentido, torna-se fundamental entender que a prática da interdisciplinaridade está inteiramente relacionada à pesquisa, conforme nos afirma Tomazetti (1998, p.13):

O professor, na perspectiva da interdisciplinaridade, não é um mero repassador de conhecimentos, mas é reconstrutor juntamente com seus alunos; o professor é, consequentemente, um pesquisador que possibilita aos alunos, também, a prática da pesquisa. A problematização como metodologia para a reconstrução de construtos dá condições ao aluno de mover-se no âmbito das teorias, das diferentes áreas do saber, construindo a teia de relações que vai torná-lo autônomo diante da autoridade do saber. O professor pesquisador constitui-se, portanto, em agente necessário de uma formação calçada na interdisciplinaridade. 
Para que ocorra a interdisciplinaridade não se discute eliminar as disciplinas, busca-se torná-las em permanente diálogo, percebendo-as dentro de suas trajetórias históricas e culturais, necessárias às práticas do processo de ensino-aprendizagem. Portanto, é importante deixar claro que, ao abraçarmos a interdisciplinaridade como metodologia no desenvolvimento do projeto, não significa abandonar as disciplinas nem nos supormos professores "pluriespecializados", mas, sobretudo, qualificar um olhar sobre a realidade escolar. Todavia, para maior consciência dessa realidade, para que os fenômenos complexos sejam observados, vistos, descritos e entendidos, torna-se cada vez mais importante a confrontação de olhares plurais na observação da situação de aprendizagem. Daí a necessidade de um trabalho interdisciplinar.

Desse modo, portanto, a preocupação do Pibid foi proporcionar de forma interdisciplinar aos professores supervisores e bolsistas ID o acesso à leitura e reflexão dos diversos gêneros textuais, promovendo a capacidade de argumentar, de se posicionar criticamente sobre o que acontece no seu entorno e ao redor do mundo. Uma compreensão para além dos muros da universidade e da sala de aula.

\section{Um relato: a Escola Municipal José Tavares Carneiro}

As atividades realizadas com alunos do $6^{\circ}$ ao $9^{\circ}$ ano do ensino fundamental da Escola Municipal José Tavares Carneiro foram desenvolvidas no projeto oficina intitulado "Lagoa Grande: minha terra quilombola", a partir das discussões e leituras encaminhadas nas reuniões de planejamento de atividades pedagógicas do Pibid Interdisciplinar.

As professoras supervisoras da Escola Municipal José Tavares Carneiro perceberam a necessidade de trabalhar a temática das relações étnico-raciais entre os educandos, em especial por estes fazerem parte de uma comunidade rural cuja população é predominantemente negra; em um dos povoados do distrito de Maria Quitéria está localizada a comunidade quilombola de Lagoa Grande. Por esses aspectos, o quilombo tornou-se tema central do trabalho, que buscou conhecer a história da comunidade quilombola a partir de suas tradições e memórias. Como destacado nas Diretrizes Curriculares Nacionais para a Educação das Relações Étnico-Raciais e para o Ensino de História e Cultura Afro-Brasileira e Africana, 
Pedagogias de combate ao racismo e a discriminações elaboradas com o objetivo de educação das relações étnico/raciais positivas têm como objetivo fortalecer entre os negros e despertar entre os brancos a consciência negra. Entre os negros, poderão oferecer conhecimentos e segurança para orgulharem-se da sua origem africana; para os brancos, poderão permitir que identifiquem as influências, a contribuição, a participação e a importância da história e da cultura dos negros no seu jeito de ser, viver, de se relacionar com outras pessoas, notadamente as negras. (Brasil, 2005, p.16)

O projeto foi elaborado com o intuito de buscar (re)conhecer o significado e a importância da identidade cultural e tradições do espaço quilombola de Lagoa Grande, no Distrito de Maria Quitéria, e, em paralelo, analisar historicamente a formação dos quilombos associados às tradições da comunidade quilombola de Lagoa Grande. Essa proposta constituiu-se em um grande desafio para as professoras supervisoras, pois tratava-se de um conteúdo que não estava elaborado nos livros didáticos e não se conheciam pesquisas sobre a referida comunidade quilombola.

As atividades da intervenção pedagógica "Lagoa Grande: Minha Terra Quilombola” foram planejadas numa perspectiva interdisciplinar envolvendo os saberes das áreas de História, Geografia e Literatura. "A orientação para o enfoque interdisciplinar na prática pedagógica implica romper hábitos e acomodações, implica buscar algo novo e desconhecido" (Thiesen, 2008, p.550). Para elas, outro desafio no trabalho proposto, pois se apresentavam novos modos pedagógicos a serem vivenciados na sala de aula.

O projeto foi desenvolvido durante 3 meses, de agosto a outubro de 2014, acontecendo semanalmente nas aulas das referidas áreas do conhecimento. Para a execução do projeto, foram seguidas algumas etapas evidenciadas a seguir.

Inicialmente, as professoras supervisoras buscaram o contato com os líderes da comunidade. Uma primeira reunião foi marcada e envolveu a participação dessas professoras e dos bolsistas ID. Esse momento foi de suma importância para as professoras supervisoras, pois nas falas dos líderes foi possível perceber a riqueza da história daquele lugar, a vivência da comunidade e suas tradições culturais. O registro desse encontro foi realizado por gravadores, câmara fotográfica e filmadora, constituindo-se num material relevante para o desenvolvimento do projeto. 
A etapa seguinte foi de sensibilização dos alunos da Escola Municipal José Tavares Carneiro, mediante um mural interativo com os seguintes questionamentos: “O que é ser quilombola?”; “O que é ser negro?”. O mural foi elaborado pelos bolsistas ID, com o objetivo de evidenciar os conhecimentos prévios dos alunos da escola para verificar o seu nível de conhecimento acerca de suas origens, a fim de planejar as intervenções nas oficinas pedagógicas. Nesse mural, os alunos responderam das mais diversas formas, de modo que foi possível identificar uma gradação de respostas, desde aquelas relativamente coerentes com os temas questionados, até outras demonstrando considerável desconhecimento acerca das suas próprias origens e da sua própria comunidade.

Identificar os conhecimentos prévios dos alunos foi uma das atividades assumidas pelas professoras supervisoras na busca pela facilitação da aprendizagem significativa. Encontrar os conhecimentos âncoras (conceitos, proposições e ideias claras, precisas, estáveis), como nos diz Ausubel (2003), é um desafio e, nesse sentido, não se tratou simplesmente da aplicação de um teste, mas encontrar um caminho que viesse a contribuir com o entendimento sobre a estrutura cognitiva dos alunos.

Cabe aqui frisar que não se tratou simplesmente de aplicar a atividade do conhecimento prévio como comumente usados nas escolas, dando apenas uma ideia superficial do conhecimento prévio do aluno. O que se quer enfatizar é que se partiu de uma necessidade para se "identificar a estrutura cognitiva do aluno" antes da instrução, seja por meio de pré-testes, entrevistas ou outros instrumentos (Moreira, 2006, p.170-171).

Consideramos que o conhecimento prévio dos alunos constitui um amplo esquema de ressignificação e sempre pode ser mobilizado durante o processo de ensino-aprendizagem. Até porque entendemos também que os estudantes trazem para os espaços escolares conhecimentos sobre variados assuntos que serão sistematizados e tratados em sala pelos professores. Nessa perspectiva, quero lembrar Regina Alegro (2008) que nos brinda com o pensamento de Ausubel sobre conhecimento prévio e aprendizagem significativa. Segundo a autora,

Para além do conhecimento veiculado no livro didático, na fala do professor, na tradição oral e nos meios de comunicação de massa, é possível reconhecer, também, o conhecimento elaborado pelo aprendiz. E mais: como estabelece a teoria da aprendizagem significativa de Ausubel e colaboradores, pode-se facilitar o 
processo de aprendizagem ao organizar-se o ensino - de História - a partir do conhecimento prévio manifesto pelos estudantes. O que o aluno já sabe, o conhecimento prévio ... é fundamental para a teoria da aprendizagem significativa, uma vez que se constitui como determinante do processo de aprendizagem... (Alegro, 2008, p.23-24)

Deste modo, tomar a abordagem teórica de Ausubel é ter como pressuposto que as características dos conhecimentos prévios dos estudantes são determinantes para novas aprendizagens, tornando a aprendizagem significativa. Em outras palavras: a atividade desenvolvida pelas professoras supervisoras, relativa aos conhecimentos prévios em sala de aula, colaborou para que a aprendizagem dos estudantes fosse significativa.

O início do projeto em sala de aula ocorreu com a apresentação de dois contos infanto-juvenis referentes ao continente africano: "As Panquecas de Mama Panya", trabalhado nas turmas de $6^{\circ}$ e $7^{\circ}$ ano; e "O Menino que Comia Lagartos”, apresentado no $8^{\circ}$ e no $9^{\circ}$ ano. Após a exposição, as professoras supervisoras fizeram uma sondagem oral com os alunos. A participação dos estudantes foi significativa. Todos, até os mais inibidos, contribuíram de forma enriquecedora para a discussão. Em seguida, os bolsistas ID distribuíram questionários que indagavam sobre o papel dos personagens no conto, de forma que os alunos também refletissem sobre seus papéis de sujeitos na comunidade. Buscou-se, assim, estabelecer uma ponte entre a África e as comunidades do Distrito de Maria Quitéria, destacando culturas, hábitos, crenças e personagens históricos nesses dois espaços.

$\mathrm{Na}$ terceira parte do desenvolvimento do projeto trabalharam-se os conceitos de quilombo e quilombola. Inicialmente, as professoras supervisoras fizeram uma "tempestade de ideias", questionando os alunos sobre o que eles pensavam a respeito da África. A maioria das respostas estava relacionada a aspectos negativos, como por exemplo, miséria, fome e escravidão, colocando-as diante de um grande desafio, ou seja, teriam de buscar e desenvolver ações que visassem modificar esses aspectos internalizados pelos alunos e que estão intimamente relacionados às suas histórias de vida.

A partir daí, buscaram fazer um contraponto exibindo imagens positivas do continente africano, demonstrando suas belezas naturais, seu desenvolvimento e sua riqueza cultural e geográfica, na perspectiva de estabelecer uma discussão sobre a contribuição da África para a construção da diversidade 
brasileira, e, em particular da baiana, região de forte influência da cultura africana.

Após essa atividade prosseguiu-se com sequências didáticas utilizando a letra da música Guerreiro do Quilombo para entrar nas discussões relativas aos conceitos de quilombo e quilombola. Para tanto, partiu-se das reflexões realizadas por Munanga e Gomes (2006, p.72), especialmente as que abordam as definições de quilombo e quilombola:

quilombo não significa refúgio de escravos fugidos. Tratava-se de uma reunião fraterna e livre, com laços de solidariedade e convivência resultante do esforço dos negros escravizados em resgatar sua liberdade e dignidade por meio da fuga do cativeiro e da organização de uma sociedade livre. Os quilombolas eram homens e mulheres que se recusavam a viver sob o regime da escravidão e desenvolviam ações de rebeldia e de luta contra o sistema.

Nesse sentido, as professoras supervisoras trabalharam com o significado da história dos quilombos, que se constituem como espaços de resistência e liberdade. Na sequência seguinte, após o estudo da música, foram discutidos aspectos referentes à temática proposta, possibilitando aos alunos uma melhor compreensão do assunto. Para a finalização dessa terceira parte, foi proposto o trabalho com poemas, e, para tal, utilizou-se um cordel denominado $O$ Quilombo dos Palmares, com o qual foram feitas atividades de leitura, reconstrução e reescrita em grupo para incentivar os alunos a construírem seu próprio poema sobre a temática estudada.

Na elaboração dos poemas, os alunos sinalizaram dificuldades na organização das ideias e também no diálogo com os colegas, sendo fundamental a intervenção das professoras supervisoras e bolsistas ID para orientá-los no processo. Superados esses entraves, os alunos conseguiram dar forma aos trabalhos propostos, produzindo poemas que retrataram as questões ligadas aos aspectos étnico-raciais.

$\mathrm{Na}$ quarta parte do trabalho desenvolveu-se a temática Quilombo Contemporâneo, que se constituiu no tema central do projeto. A atividade foi iniciada com uma palestra ministrada pelo líder da Comunidade Quilombola de Lagoa Grande, o sr. José Cassiano. Nesse momento, professores, bolsistas e alunos ouviram atentamente a história daquele lugar, o quilombo, seu desenvolvimento, suas lutas e resistências que permanecem até hoje. A partir daquele 
depoimento, evidenciou-se a importância da memória dos mais velhos para a reconstituição do processo histórico das comunidades remanescentes quilombolas. Aqui vale lembrar Ecléa Bosi (1987) que, ao dar voz aos idosos, os convida a apresentarem suas lembranças mais antigas e, com elas, recuperar um tempo e um modo de viver que, de outra forma, estariam perdidos para sempre.

A partir dessa escuta, levou-se a discussão para a sala de aula e logo em seguida foi exibida aos alunos da escola a história em quadrinhos sobre a origem da comunidade quilombola estudada, construída pelas professoras supervisoras e pelos bolsistas ID. Com a realização do debate sobre o tema, houve o envolvimento dos alunos com a atividade proposta, valorizando e potencializando a sua história local.

Com o prosseguimento do projeto, exibiu-se o vídeo sobre a bata do feijão, ${ }^{1}$ produzido na própria comunidade quilombola, a partir do qual os alunos foram instigados a se posicionarem sobre aquela atividade, estimulando-os a entenderem a importância e a necessidade da preservação dessa manifestação cultural para a comunidade quilombola e também para as suas vidas. Ao final dessa sequência didática, foi proposto aos alunos um estudo com imagens da comunidade com o objetivo de verificar o sentimento de pertencimento ao local e o conhecimento de suas memórias na perspectiva de entenderem suas heranças culturais.

A última etapa do projeto consistiu na exposição de fotografias, intitulada Lagoa Grande: Novos Olhares, durante a qual se apresentou para a comunidade escolar e local alguns dos resultados obtidos a partir das atividades desenvolvidas. $\mathrm{Na}$ exposição de fotografias foi retratado o dia a dia dos moradores da comunidade estudada, com suas significâncias e particularidades, utilizando as potencialidades do uso de imagens que retratam parte da história da comunidade, levando os participantes a refletirem acerca da fotografia e sua relação com a memória:

a fotografia revoluciona a memória, pois possibilita a sua multiplicação, dando uma precisão ... que permite guardar a memória do tempo ... constituindo um patrimônio cultural que pode explicar as singularidades dos materiais, do cenário, dos seres, do sujeito e grupos retratados e da própria sociedade. (Castro, s.d., p.9) 
Durante a exposição fotográfica, alunos do $6^{\circ}$ ao $9^{\circ}$ ano declamaram poesias elaboradas por eles. A atividade contou também com a participação do grupo de samba de roda Quixabeira de Lagoa da Camisa ${ }^{2}$ e do grupo de percussão Juventude Negra da Escola José Tavares, com apresentações de músicas constituindo-se em um rico momento da expressão afro, demonstrando a força da tradição e das manifestações da cultura sertaneja e a performance que evoca as suas raízes.

Ao final da visita à exposição, alunos, professores e os próprios moradores da comunidade relataram suas impressões em um mural interativo. As falas refletiram alegria, satisfação e muita emoção, principalmente por parte dos moradores de Lagoa Grande, uma vez que muitos perceberam a riqueza e a valorização daquele lugar.

Desse modo, as professoras supervisoras concluíram que o trabalho desenvolvido contribuiu para o fortalecimento da identidade étnica dos educandos da escola municipal e dos moradores da comunidade quilombola de Lagoa Grande, igualmente partícipes dessa experiência. Conhecer a história e valorizar as tradições e a memória dessa comunidade possibilitou aos alunos se reconhecerem como sujeitos históricos e pertencentes àquela localidade. Nesse sentido, as questões acerca do estudo da história local também emergiram nas salas de aula, constituindo um elemento desafiador, como também enriquecedor para a prática pedagógica, ou, como diz Barbosa (2006, p.66-67):

o ensino de história local ganha significado e importância no ensino fundamental, exatamente pela possibilidade de introduzir e pronunciar a formação de um raciocínio histórico que contemple não só o indivíduo, mas a coletividade, aprendendo as relações sociais que ali se estabelecem, na realidade mais próxima. Apresenta-se a abordagem da história cotidiana e dos fatos presentes introduzindo a possibilidade de resgatar o passado, através de variadas formas, entre elas, o uso de fontes disponíveis na própria localidade - quando existirem: os livros, a literatura de cordel, músicas e poesias, as fotografias, o patrimônio histórico material e imaterial, os documentos dos arquivos, bem como, descobrindo e explorando as fontes vivas através de depoimentos orais.

Para as professoras supervisoras o Pibid Interdisciplinar possibilitou mudanças significativas em suas práticas pedagógicas, conforme depoimento: 
Salientamos em primeiro lugar o diálogo e a troca de saberes entre a educação básica e a universidade, que representou para nós a oportunidade de enriquecimento no campo teórico, através de estudo de textos referentes à temática desenvolvida na escola. Para além dessas discussões, percebemos que o ato de planejar nossas atividades sofreu modificações relevantes, no que diz respeito à sistematização das sequências didáticas, a utilização de diversas fontes metodológicas e a elaboração do material didático. Oportunizou também o contato direto com a comunidade, através das visitas e entrevistas realizadas, percebendo assim as vivências, lutas e tradições da população quilombola.

O destaque dado pelo depoimento das professoras supervisoras relativo ao intercâmbio entre a universidade e a escola básica evidenciou que o permanente diálogo desmitifica a hierarquização entre essas instituições de formação e favorece a troca de conhecimentos, contribuindo com um processo de ensino e aprendizagem significativo e contextualizado. É, portanto, uma fala que indica um menor distanciamento entre o saber acadêmico e o saber produzido na escola.

\section{Outro relato: o Colégio Estadual Prof a Maria José de Lima Silveira}

Alfabetização e letramento dos estudantes brasileiros ainda são questões de fundamental importância para o Brasil deste começo do século XXI. As avaliações nacionais (Provinha $\mathrm{Brasil}^{3} \mathrm{e} \mathrm{Saeb}^{4}$ ) de ensino enfocam o processo de alfabetização (Bonamino; Coscarelli; Franco, 2002), revelando o atraso educacional do país, refletido no resultado abaixo da média nas avaliações internacionais do Programa Internacional de Avaliação de Alunos (Pisa). (Inep, 2003; OECD, 2000, 2006, 2010, 2012). O incompleto processo de letramento dos estudantes interfere diretamente na sua formação enquanto indivíduos, no processo de tomada de consciência da realidade, neste inserida a questão do lugar (Carlos, 2007).

Dessa forma, pensar o lugar é possibilidade de repensar a identidade que, no caso desse colégio estadual, é questão necessária tendo em vista a sua obrigação em inserir-se nas concepções da Educação do Campo (Caldart, 2012), posto que está localizado em área rural. 
Inseridos no contexto de letramento e identidade do campo, foi proposto o projeto Oficina de Letramento: filhos do Lugar, voltado para os estudantes do $6^{\circ}$ ano do Colégio Profa Maria José de Lima Silveira, localizado no distrito de Maria Quitéria, em Feira de Santana.

Na primeira parte do projeto ocorreu, por meio de técnicas etnográficas, a observação participante (Lüdke; André, 1986), na qual os bolsistas ID frequentaram o Colégio com o intuito de conhecer o universo escolar em suas várias dimensões, fossem elas pedagógicas e/ou de gestão. Além desses aspectos, também observaram aulas e se relacionaram com os estudantes da escola. Em paralelo a essa etapa, analisaram o Plano de Intervenção Pedagógica do Colégio (PIP), no qual há informações referentes ao diagnóstico pedagógico, com dados descritivos como taxas de repetência, evasão, defasagem idade/ série, bem como o plano estratégico para sanar tais problemas. Ainda nessa etapa, solicitou-se a um dos cordelistas da região, sr. Domingos José da Paixão, conhecido como "Domingos Santeiro", a elaboração de um cordel que descrevesse São José, para ser trabalhado na Oficina.

O cordel, intitulado São José: perfis históricos e geográficos de sua gente, foi dividido em três partes: Água, São José e Povo. A primeira tratou das lagoas da região e de sua importância para a realidade dos moradores; a segunda apontou as diversas comunidades que constituem o distrito; por fim, a terceira descreveu figuras importantes de São José, como vaqueiros, donas de casa, professores, religiosos e Maria Quitéria. ${ }^{5}$ A segunda etapa do projeto foi dedicada à apresentação do cordel aos estudantes da escola. Para tanto, estabeleceu-se um estreito diálogo com a Literatura, inserindo o cordel no projeto de Leitura da disciplina Língua Portuguesa. Ainda nessa etapa, os estudantes produziram, nas aulas de Ciências, o texto identitário com o tema "Quem sou eu?”, no qual expuseram sua visão a respeito deles próprios e, consequentemente, do lugar onde moravam.

A terceira fase do projeto consistiu na realização da Oficina de Letramento. Os estudantes foram divididos em três grupos, de acordo com a turma a que pertenciam. Cada grupo ficou responsável por aprofundar uma das partes do cordel. Assim, o grupo I ficou responsável pela Água; o grupo II, por São José, e o grupo III, pelo Povo. Realizaram-se com cada grupo três encontros que foram conduzidos pelos bolsistas ID sob orientação do professor supervisor. 
No primeiro encontro realizou-se uma breve apresentação das características do gênero cordel e de sua história. Depois, realizou-se um ditado das estrofes que seriam trabalhadas em cada grupo, com o objetivo de desenvolver a percepção fonética da língua e a habilidade de escrita, observando também as dificuldades mais comuns para trabalhá-las no encontro seguinte.

O segundo encontro foi dedicado à autocorreção das atividades, que não só estimulou o protagonismo dos estudantes frente ao seu trabalho, mas os levou a refletir sobre os pontos de dificuldade que precisavam ser trabalhados. Além disso, realizou-se a leitura em grupo das estrofes trabalhadas. A leitura em grupo foi a estratégia encontrada para contornar a negativa de leitura por parte da maioria dos estudantes que, por não se sentirem seguros frente aos colegas, negaram-se a participar das leituras em voz alta. Também se discutiram ideias tratadas pelo cordel, como identidade campesina, sentimento de pertencimento, valorização do lugar e da identidade, importância das lagoas para a comunidade e importância do hábito de leitura e escrita para o efetivo letramento.

Assim, como nos diz Magda Soares em seu texto Letramento e alfabetização: as muitas facetas,

o reconhecimento de que tanto a alfabetização quanto o letramento têm diferentes dimensões, ou facetas, a natureza de cada uma delas demanda uma metodologia diferente, de modo que a aprendizagem inicial da língua escrita exige múltiplas metodologias, algumas caracterizadas por ensino direto, explícito e sistemático - particularmente a alfabetização, em suas diferentes facetas -, outras caracterizadas por ensino incidental, indireto e subordinado a possibilidades e motivações das crianças... (Soares, 2003, p.16)

As atividades desenvolvidas abarcaram também o problema da alfabetização, como não poderia deixar de ser, visto que o letramento insere-se no processo de alfabetização, não podendo serem dissociados, especialmente na Bahia, onde as habilidades de ler e escrever não são devidamente trabalhadas nas séries iniciais.

A esse respeito, Soares (2003) contribui com reflexões fundamentais para pensarmos as questões de letramento e alfabetização. Desse modo, para ela,

Dissociar alfabetização e letramento é um equívoco porque, no quadro das atuais concepções psicológicas, linguísticas e psicolinguísticas de leitura e escrita, a en- 
trada da criança (e também do adulto analfabeto) no mundo da escrita ocorre simultaneamente por esses dois processos: pela aquisição do sistema convencional de escrita - a alfabetização - e pelo desenvolvimento de habilidades de uso desse sistema em atividades de leitura e escrita, nas práticas sociais que envolvem a língua escrita - o letramento. (Soares, 2003, p.14)

\section{E acrescenta:}

a necessidade de rever e reformular a formação dos professores das séries iniciais do ensino fundamental, de modo a torná-los capazes de enfrentar o grave e reiterado fracasso escolar na aprendizagem inicial da língua escrita nas escolas brasileiras. (ibidem, p.16)

O último encontro trabalhou o entendimento dos estudantes da escola acerca do texto do cordel, o lugar (São José, campo) e sua identidade por meio do desenho. Os desenhos foram organizados em cartazes expostos em cada sala de modo que os alunos pudessem observar e discutir as diferentes percepções e modos de representação dos colegas.

Merece destaque a opinião dos professores supervisores sobre o projeto desenvolvido no colégio. Para eles

A perspectiva interdisciplinar foi um elemento integrador do processo de ensino-aprendizagem, tendo em vista que o aproveitamento de nosso trabalho esteve e está diretamente vinculado ao domínio de habilidades trabalhadas nas disciplinas envolvidas no Pibid. O projeto nos propiciou diversos questionamentos e inquietações que nos desafiam a pensar em como agir enquanto docentes no intuito de desenvolver um trabalho realmente significativo no espaço da escola.

O relato põe em evidência o compromisso dos professores com o Pibid e a mobilização interna provocada pelo trabalho desenvolvido, gerando desafios à prática docente, ressignificando papéis que, por consequência, reoxigenam o fazer pedagógico.

\section{Algumas Considerações}

O projeto Pibid Interdisciplinar (História, Geografia e Letras) da Universidade Estadual de Feira de Santana (UEFS), desenvolvido na Escola 
Municipal José Tavares e no Colégio Estadual Maria José de Lima Silveira, durante o ano de 2014, contribuiu para o desenvolvimento dos docentes em formação (ou seja, os bolsistas ID) das áreas envolvidas, articulando teoria e prática, permitindo a aproximação do ambiente escolar e da realidade cotidiana.

As duas escolas foram o lócus em que os licenciandos tiveram o contato com a realidade escolar, permitindo-lhes refletir sobre as diferentes formas de ensinar e pesquisar as estratégias que irão utilizar em suas práticas docentes.

A experiência com a pesquisa em conexão com a prática docente produziu, ao longo das atividades, resultados significativos para o ensino-aprendizagem, bem como impacto na comunidade escolar, como apontam os depoimentos dos professores supervisores, após todos esses meses de atividades em sala de aula:

O subprojeto Interdisciplinar proporcionou o desenvolvimento de atividades no espaço escolar, com diálogo enriquecedor entre as várias áreas do conhecimento (História, Geografia e Literatura). Nessa perspectiva, observamos avanços significativos em nossa prática pedagógica, possibilitando um novo olhar na produção do conhecimento. Salientamos, também, a contribuição desse subprojeto na formação de professores, pois os bolsistas ID tiveram a oportunidade de planejar e aplicar atividades voltadas para a história local. (S., professora supervisora, 2014)

Acredito que o Pibid Interdisciplinar em suas ações buscou trabalhar questões fundamentais da educação básica como a habilidade de escrita, leitura e interpretação da realidade na qual estamos inseridos. Além disso, o subprojeto interdisciplinar desenvolveu diversas atividades voltadas à valorização do local e à afirmação da identidade. Para a formação docente, o subprojeto incentivou a formação de professores-pesquisadores de sua própria atividade no ambiente escolar, bem como incentivou e refletiu a respeito do caráter interdisciplinar inerente à atividade em sala de aula. Para minha unidade escolar, o subprojeto, sob minha supervisão, desenvolveu atividades voltadas justamente para um dos maiores problemas diagnosticados pela própria escola que é o domínio de habilidade básicas de letramento por parte dos estudantes. Assim, o subprojeto inseriu-se verdadeiramente na realidade da unidade escolar de modo a ajudar nos mais importantes desafios tidos pela unidade escolar... (L., professor supervisor, 2014) 
Os dois relatos expressam o sentimento de valorização, por parte dos professores, pelo trabalho desenvolvido e pelo compromisso com a pesquisa e, especificamente, com o papel de orientadores dos futuros professores. As ações desenvolvidas contribuíram para a formação dos bolsistas ID por meio de um processo reflexivo, no qual todos os sujeitos envolvidos modificaram e construíram seus saberes. A pesquisa-ação contribuiu para a melhora das ações propostas e permitiu aos sujeitos envolvidos realizarem reflexões sobre suas práticas.

Um docente envolvido com o seu fazer pedagógico tem sede do conhecimento, sede de pesquisar e de buscar incessantemente aprender o que ainda não sabe. Além disso, em sua lida diária, no ambiente escolar depara com os diferentes aspectos da realidade que se apresenta. Professores e alunos aprendem juntos; ambos aprendem quando pesquisam. Como diz Paulo Freire,

Fala-se hoje, com insistência, no professor pesquisador. No meu entender, o que há de pesquisador no professor não é uma qualidade ou uma forma de ser ou de atuar que se acrescente à de ensinar. Faz parte da natureza da prática docente a indagação, a busca, a pesquisa. O de que se precisa é que, em sua formação permanente, o professor se perceba e se assuma, porque professor, como pesquisador. (Freire, 2011, p.30)

Ao fomentar a articulação entre a Educação Básica e a universidade, o Pibid Interdisciplinar da UEFS vem contribuindo com a formação inicial e continuada de 28 estudantes bolsistas ID e 5 professores supervisores que compõem a equipe e que aceitaram o desafio de ousar na sala de aula e de tornarem-se pesquisadores e educadores de sua própria prática, comprometidos com o projeto e buscando, constantemente, a compreensão e melhoria das ações.

Considera-se que a proposta de envolver os conhecimentos e a experiência e prática dos professores da rede pública e licenciandos em História, Geografia e Letras certamente tem sido significativa, porquanto tem permitido ao estudante de licenciatura envolvido no programa a possibilidade de conectar a teoria vivenciada na universidade à prática docente no ambiente da escola, avançando e fazendo uso de novas abordagens e métodos de ensino das licenciaturas envolvidas.

Ao mesmo tempo, o Pibid UEFS tem contribuído para a formação continuada dos professores supervisores, proporcionando a troca de experiências e a atualização das leituras referentes ao ensino de História, Geografia e Letras 
na perspectiva interdisciplinar, permitindo a (re)elaboração de práticas pedagógicas mais adequadas aos fazeres e saberes que envolvem o ensino, transformando o exercício docente.

\section{REFERÊNCIAS}

ALEGRO, Regina Célia. Conhecimento prévio e aprendizagem significativa de conceitos históricos no Ensino Médio. Tese (Doutorado) - Universidade Estadual Paulista "Júlio de Mesquita Filho" (Unesp). Marília, 2008.

AUSUBEL, David Paul. Aquisição e retenção de conhecimentos: uma perspectiva cognitiva. Lisboa: Plátano, 2003.

BARBOSA, Vilma de Lurdes. Ensino de História Local: redescobrindo sentidos. SAECULUM - Revista de História, João Pessoa, v.15, jul./dez. 2006.

BONAMINO, Alicia; COSCARELLI, Carla; FRANCO, Creso. Avaliação e letramento: concepções de aluno letrado subjacentes ao SAEB e ao PISA. Educação \& Sociedade, v.23, n.81, p.91-113, 2002.

BOSI, Ecléa. Memória e sociedade, lembranças de velhos. São Paulo: T. A. Queiroz, 1987.

BRASIL. Ministério da Educação (MEC). Diretrizes Curriculares Nacionais para a Educação das Relações Étnico-Raciais e para o Ensino de História e Cultura Afro-Brasileira e Africana. Brasília, 2005.

CALDART, Roseli Salete. Educação do campo. In: ___. Dicionário da educação do campo. Rio de Janeiro: Expressão Popular, 2012. p.257-265.

CARLOS, Ana Fani Alessandri. O lugar no/do mundo. São Paulo: Hucitec, 1996.

CASTRO, Shoraia de. A valorização da História Local e do Cotidiano. s.d., p.9. Disponível em: www.diaadiaeducacao.pr.gov.br/portals/pde/arquivos/1825-8.pdf; Acesso em: 14 mar. 2015.

FREIRE, Paulo. Pedagogia da autonomia. 43.ed. São Paulo: Paz e Terra, 2011.

INEP. Instituto Nacional de Estudos e Pesquisas Educacionais Anísio Teixeira. http:// portal.inep.gov.br/internacional-novo-pisa-resultados; Acesso em: 15 fev. 2015.

LÜDKE, Menga; ANDRÉ, Marli de. Pesquisa em educação: abordagens qualitativas. Rio de Janeiro: Ed. Pedagógica e Universitária, 1986.

MOREIRA, Marco Antônio. A teoria da aprendizagem significativa e sua implementação em sala de aula. Brasília: Ed. UnB, 2006.

MUNANGA, Kabengele; GOMES, Nilma Lino. O negro no Brasil de hoje. São Paulo: Global, 2006. (Coleção Para Entender).

OECD. Brazil: country note. Results from PISA 2012. Disponível em: http://www.oecd. org/pisa/keyfindings/PISA-2012-results-brazil.pdf; Acesso em: 10 mar. 2015. 
OECD. Executive Summary PISA 2006: Science Competencies for Tomorrow's World. 2007. Disponível em: http://eric.ed.gov/?id=ED504064; Acesso em: 10 mar. 2015.

OECD. PISA 2009. Results: Executive Summary. 2010. Disponível em: http://www.oecd.org/pisa/pisaproducts/46619703.pdf; Acesso em: 10 mar. 2015.

PINHEIRO, Sandra Cristina Queiroz. Álbum (8 fotografias coloridas, dimensões variadas), 2014. (inédito).

PISA 2000. Relatório nacional. Brasília, 2001. Disponível em: http://www.oecd.org/education/school/programmeforinternationalstudentassessmentpisa/33683964.pdf; Acesso em: 10 mar. 2015.

SOARES, Magda. Letramento e alfabetização: as muitas facetas. In: REUNIÃO ANUAL DA ANPEd, 26. Poços de Caldas, MG, 5-8 out. 2003.

THIESEN, Juares da Silva. A interdisciplinaridade como um movimento articulador no processo ensino-aprendizagem. Revista Brasileira de Educação, v.13, n.39, set./dez. 2008.

TOMAZETTI, Elisete. Estrutura conceitual para uma abordagem do significado da interdisciplinaridade: um estudo crítico. UFSM, n.10, p.1-43, 1998.

\section{ANEXOS}

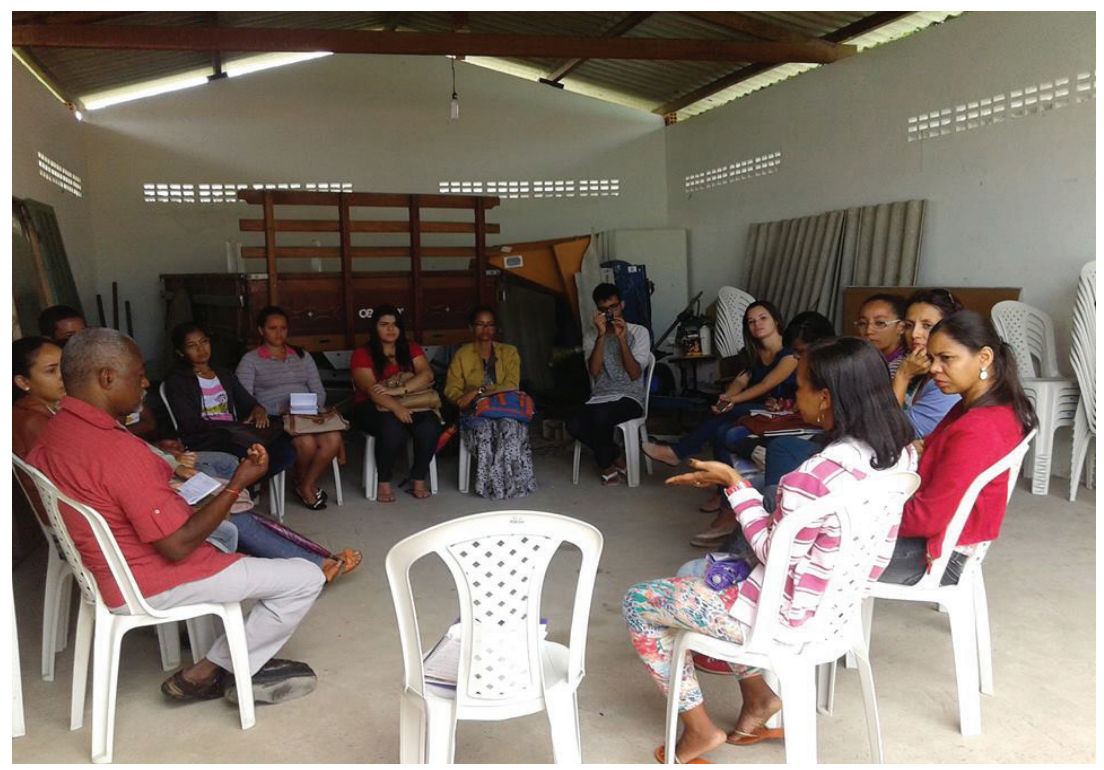

Figura 1 - Visita dos bolsistas e supervisoras à Comunidade de Lagoa Grande. 19,5 x 25,4 cm. Fonte: Pinheiro, 2014 


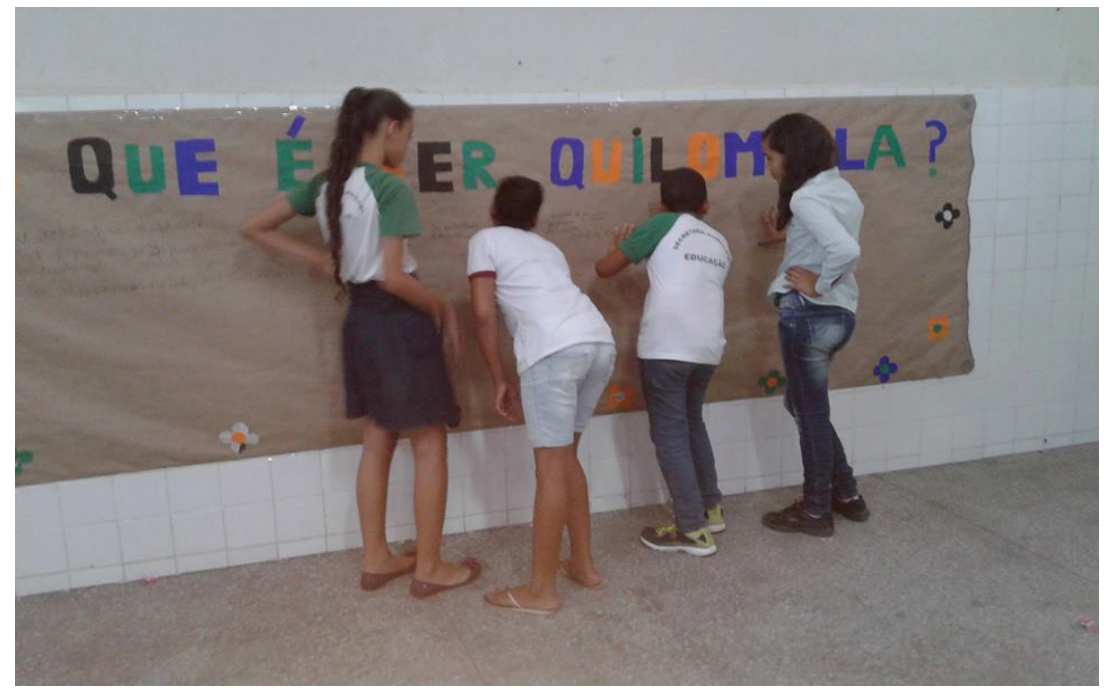

Figura 2 - Mural interativo: O que é ser negro? O que é ser quilombola? 19,5 x 25,4 cm. Fonte: Pinheiro, 2014.

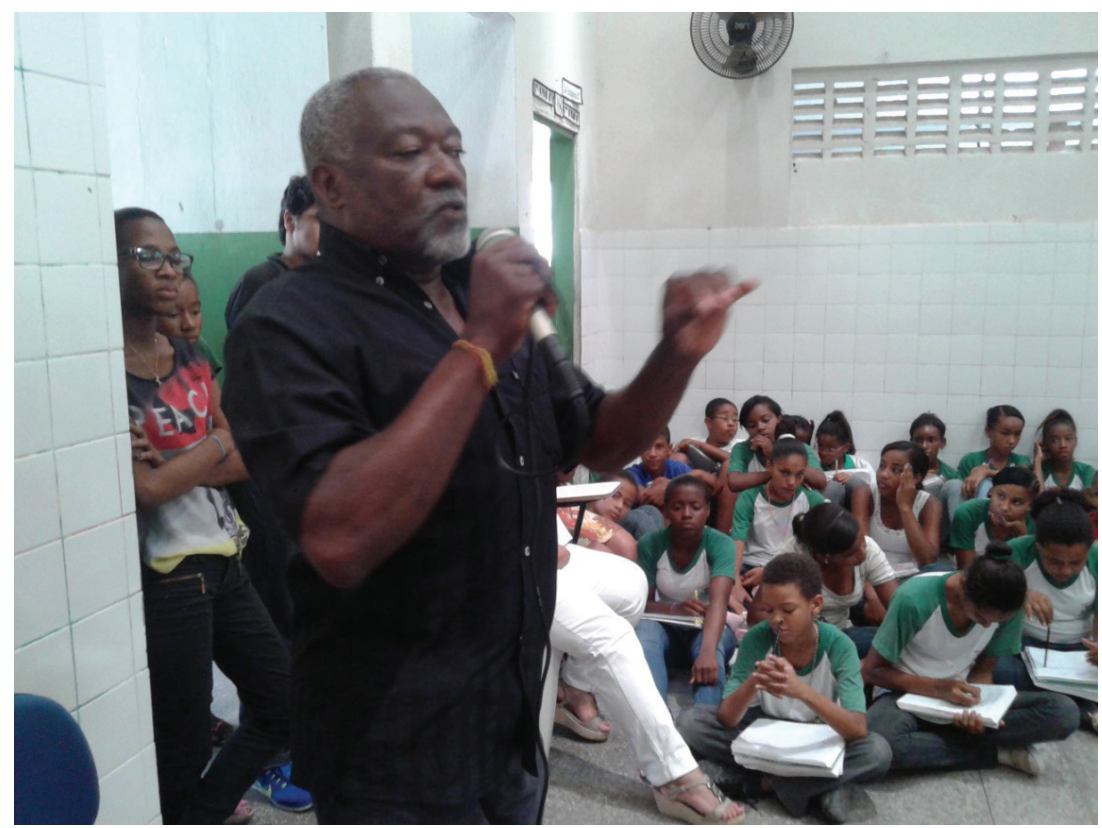

Figura 3 - Palestra com o líder da Comunidade de Lagoa Grande. 19,5 x 25,4 cm. Fonte: Pinheiro, 2014. 


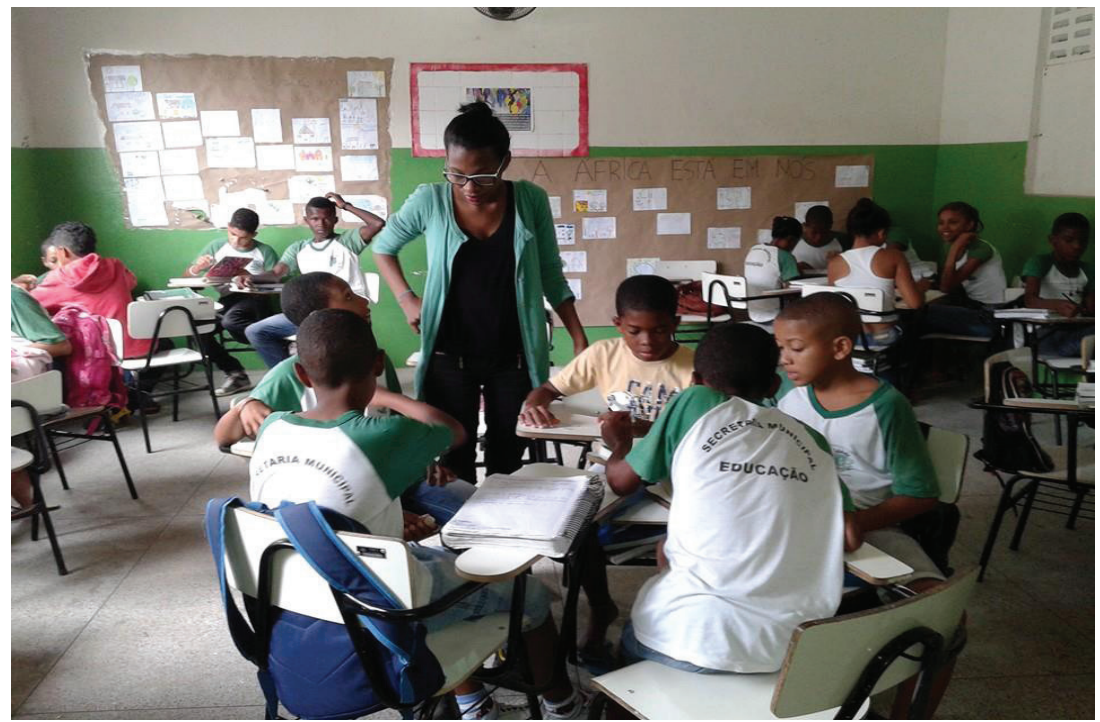

Figura 4 - Elaboração dos poemas pelos alunos. 19,5 x 25,4 cm. Fonte: Pinheiro, 2014.

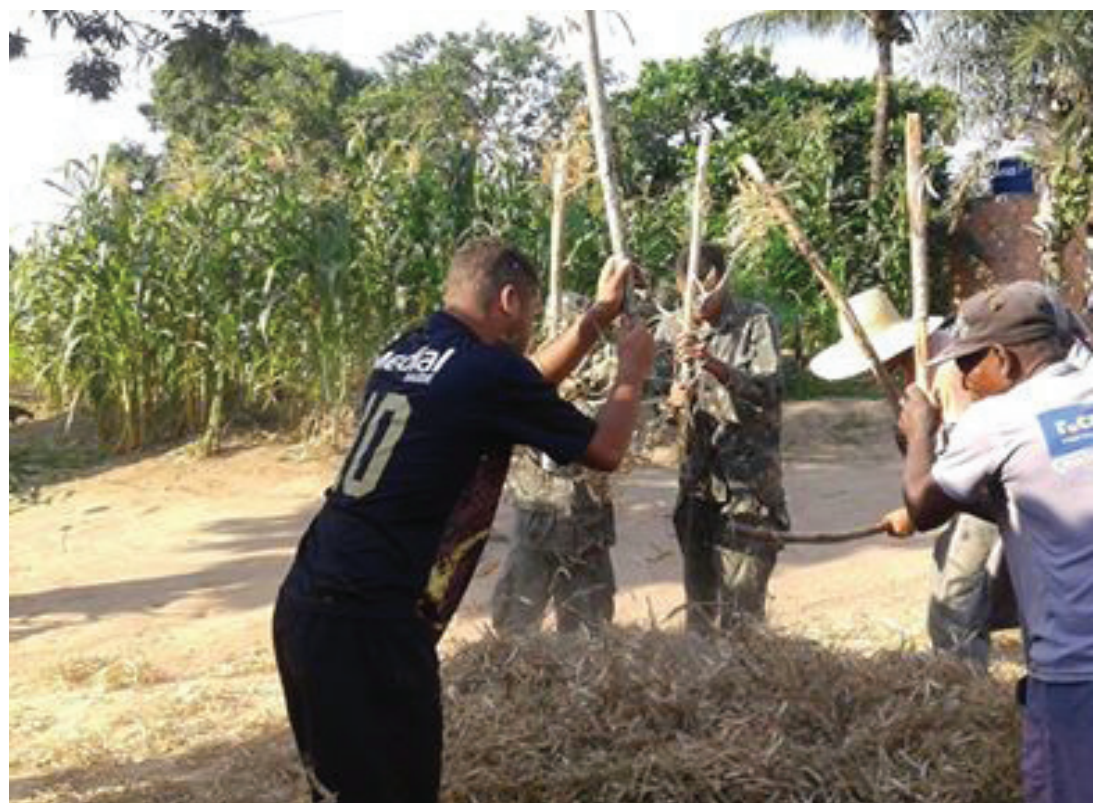

Figura 5 - Moradores de Lagoa Grande realizando a bata do feijão. 19,5 x 25,4 cm. Fonte: Pinheiro, 2014. 


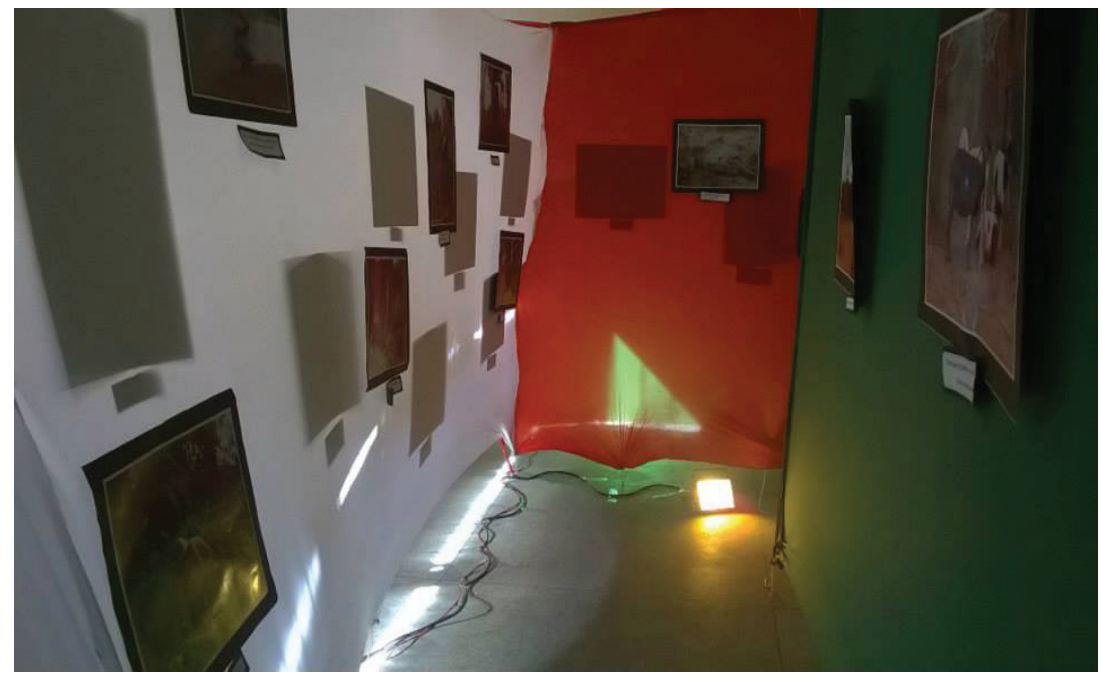

Figura 6 - Exposição de fotografias. 19,5 x 25,4 cm. Fonte: Pinheiro, 2014.

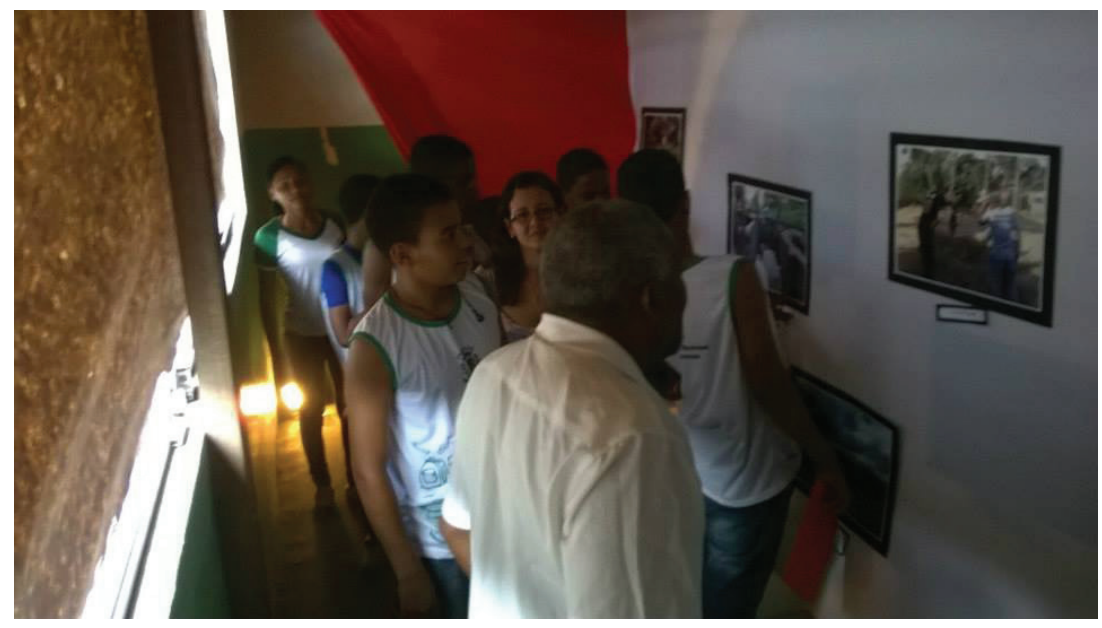

Figura 7 - Exposição de fotografias. 19,5 x 25,4 cm. Fonte: Pinheiro, 2014. 


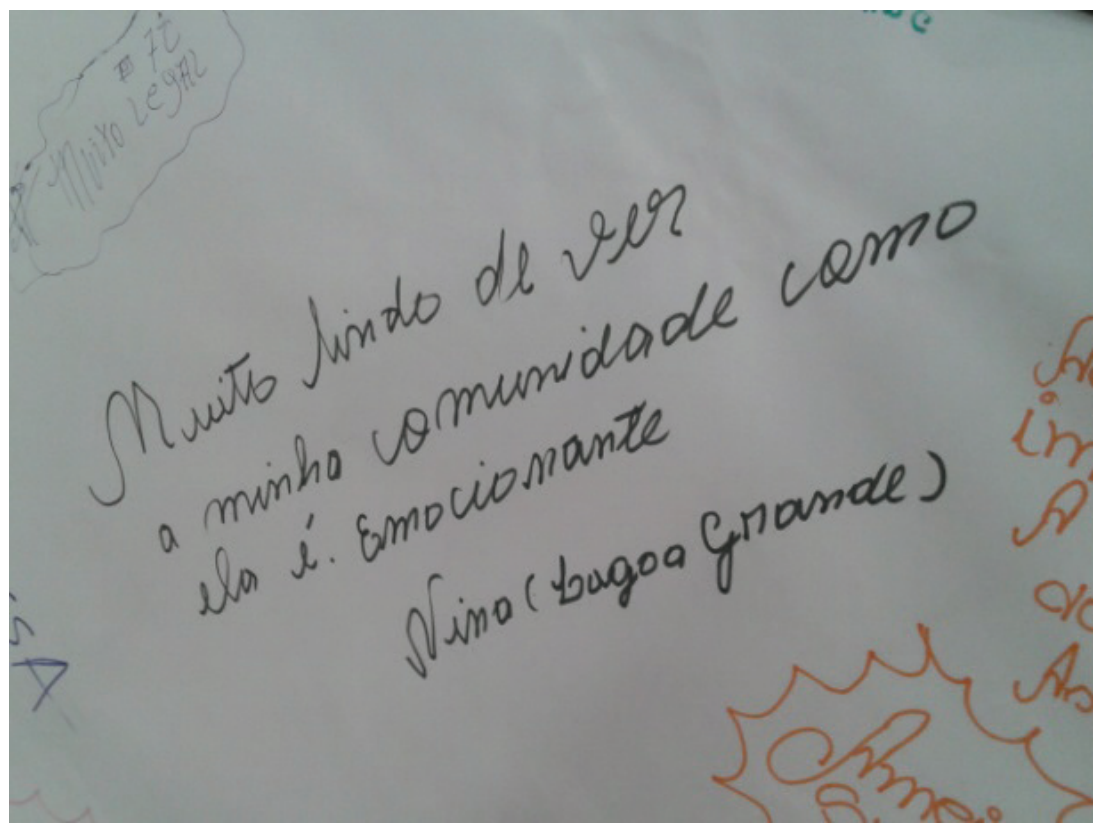

Figura 8 - E aí? Me conta o que você acha? 19,5 x 25,4 cm. Fonte: Pinheiro, 2014.

\section{NOTAS}

${ }^{1}$ A "bata do feijão" é uma atividade desenvolvida no quilombo, na qual se coloca o feijão para secar. Depois de as vagens estarem secas, todos os homens e mulheres ajudam no trabalho de debulhar. Os homens fazem uma grande roda com um pau na mão e começam a bater na vagem seca. Enquanto os homens vão batendo nas vagens e juntando com os pés as partes que se espalham, as mulheres seguem em fila, retirando com uma peneira as cascas que sobraram. Depois das batas, é comum as mulheres entoarem suas cantigas de roda enquanto peneiram. Uma das canções comumente cantadas nessas ocasiões, Amor de longe, se tornou bastante conhecida por intermédio do grupo Quixabeira de Lagoa da Camisa: "Amor de longe, benzinho. É favor não me querer, benzinho. Dinheiro eu não tenho, benzinho. Mas carinho eu sei fazer até demais". Adaptado de: http://paralapraca.org.br/index. php/paralapraca-indica/livros/272-paisagem-festiva-bata-do-feijao-ba; Acesso em: 30 mar. 2015.

${ }^{2}$ O grupo Quixabeira de Lagoa da Camisa faz registro da riqueza e diversidade musical do sertão baiano em sambas de roda, chulas, samba martelo, batuques, reisados e cantigas de roda que são alguns dos ingredientes que compõem a música, o canto, a dança e os acompanhamentos com as palmas da mão. Reunidos oficialmente desde 1991, os dez membros 
do Grupo têm como principal objetivo passar para os mais jovens a continuidade das suas manifestações culturais como forma de transmissão e preservação da sua cultura que é predominantemente afro. As canções fazem parte da experiência cotidiana e surgem a partir da relação com o meio físico, com a comunidade e com o mundo. Essas manifestações, cada uma a seu modo e no contexto onde é exercitada, apresenta uma concepção de mundo, uma forma de organização da relação dos membros da comunidade com o seu sítio simbólico de pertencimento e com sua ancestralidade. Texto adaptado de: http://sandrosantana.tnb.art.br/; Acesso em: 30 mar. 2014. Para conhecer mais sobre Quixabeira de Lagoa da Camisa ver: https://myspace.com/quixabeiradelagoadacamisa/video/na-comunidade-de-lagoa-da-camisa-/104993342.

${ }^{3}$ A Avaliação da Alfabetização Infantil - Provinha Brasil é uma avaliação diagnóstica que visa investigar o desenvolvimento das habilidades relativas à alfabetização e ao letramento em Língua Portuguesa e Matemática, desenvolvidas pelas crianças matriculadas no $2^{\circ}$ ano do ensino fundamental das escolas públicas brasileiras. Disponível em: http://provinhabrasil.inep.gov.br/; Acesso em: 30 mar. 2014.

${ }^{4}$ O Sistema de Avaliação da Educação Básica (Saeb), conforme estabelece a Portaria no 931, de 21 mar. 2005, é composto por dois processos: a Avaliação Nacional da Educação Básica (Aneb) e a Avaliação Nacional do Rendimento Escolar (Anresc). Disponível em: http://portal.inep.gov.br/saeb; Acesso em: 30 mar. 2014.

${ }^{5}$ Maria Quitéria de Jesus Medeiros, filha de um fazendeiro português, nasceu em São José, distrito de Feira de Santana, na Bahia, em 1792. Foi uma militar brasileira, considerada a primeira mulher a assentar praça numa unidade militar das Forças Armadas Brasileiras e a primeira mulher a entrar em combate pelo Brasil, em 1823, quando, vestida de homem e usando o nome do cunhado, José Cordeiro de Medeiros, lutou ao lado dos outros soldados para derrotar os colonizadores portugueses e consolidar a independência do Brasil. Adaptado de: http://www.baraoemfoco.com.br/barao/coluna/mariaquiteria.htm; Acesso em: 28 mar. 2015.

Artigo recebido em 22 de maio de 2015. Aprovado em 6 de junho de 2015. 